\title{
Vergel de perfectísimas flores. Las dominicas valencianas de Carcaixent según fray José Agramunt
}

\section{Vergel de perfectísimas flores. The dominicans nuns of Carcaixent trought the work of fray José Agramunt}

\author{
Emilio Callado Estela \\ ecallado@uchceu.es
}

Universidad CEU Cardenal Herrera

Resumen: El presente trabajo pretende rescatar del olvido una de los conventos dominicanos más desconocidos del ámbito valenciano. En concreto, el de Corpus Christi de la localidad de Carcaixent, en la ribera del rio Xúquer. Fundación tardobarroca ésta, erigida en 1654, objeto ya en el siglo XVIII del interés histórico de uno de sus primeros confesores. Hablamos de fray José Agramunt, autor del inédito Parayso de Dios. Idea del religiosíssimo monasterio de señoras dominicas de la real villa de Carcaxente, analizado en las siguientes páginas en el marco de la vida y producción literaria del citado religioso.

Palabras clave: Orden de Predicadores, Monjas, Siglos XVII y XVIII, Valencia

\begin{abstract}
In this present work, we aim to recover one of the forgotten dominican convents from Valencia. More specifically, the convent of the Corpus Christi located in Carcaixent, on the banks of the River Xúquer. This late Baroque convent was built in 1654. By the eighteenth century, one of his confessors had already made clear its historical interest. We are referring to fray José Agramunt, the author of the unpublished work, Parayso de Dios: Idea del Religiosíssimo Monasterio de Señoras Dominicas de la Real Villa de Carcaxente, analysis in the following pages the life and literal works of the aforementioned religious.
\end{abstract}

Keywords: Order of Preachers, Nuns, $17^{\text {th }}$ and $18^{\text {th }}$ centuries, Valencia

\footnotetext{
* Este artículo forma parte del Proyecto de Investigación La Catedral Ilustrada. Iglesia, sociedad y cultura en la Valencia del siglo XVIII, financiado por el Ministerio de Economía y Comptetitividad del Gobierno de España (HAR 2012/32893).
} 


\section{Introducción}

Con ocasión de anteriores incursiones en el tema objeto de estas páginas, recordamos que la preocupación por las órdenes religiosas, como objeto de investigación, análisis e interpretación histórica, tiempo ha que empezó a liberarse de tonos hagiográficos tradicionales, planteamientos y lenguajes clericales para convertirse en territorio de historiadores de oficio (Egido 2011: 22-23). Ya en la década de los sesenta del pasado siglo los monasterios medievales franceses eran estudiados sistemáticamente con criterios acordes a los nuevos tiempos. En España, donde la historia del clero regular abandonó los claustros con posterioridad, ha sido uno de los capítulos más y mejor atendidos por la historiografía de las últimas décadas, al menos para la época moderna (Martínez Ruiz 2004). Aunque no todas las religiones ni todos los lugares se han beneficiado por igual de esta tendencia. Los dominicos de la Provincia de Aragón, por ejemplo, continúan sin suscitar suficiente interés entre los investigadores, pese a los meritorios esfuerzos de algunos trabajos colectivos coordinados por R. Ma Alabrús (2011, 2012 y 2013). Ni siquiera los grandes establecimientos blanquinegros, diseminados a lo largo y ancho de los territorios de la antigua Corona de Aragón, cuentan con estudios adecuados. No los masculinos, desde luego. Pero tampoco los femeninos, prácticamente ajenos al protagonismo cobrado por las mujeres en el proceso de renovación temática y metodológica experimentado por la Historia (Amelang 1990) y su impacto en el análisis de las órdenes religiosas. ${ }^{1}$

Quizá sea el caso valenciano uno de los más elocuentes. De los conventos monjiles aquí erigidos por la orden de Predicadores desde la Reconquista cristiana, poco se sabe más allá de los datos consignados en las obras de carácter general que tratan de pasada algún aspecto de la vida monacal (Sarthou Carreres 1943), a menudo desde una perspectiva eminentemente economicista (Cabanes Pecourt 1974); o en las propias crónicas dominicanas, de las que la obra clásica de F. Diago constituye el mejor exponente (Diago 1599). A semejante panorama, sin embargo, escaparían los asentados en la capital del Turia. Ya con anterioridad a la debacle documental contemporánea, tuvieron algunos de ellos la fortuna de ser historiados a cargo de la orden, aunque desde criterios alejados todavía del rigor científico. ${ }^{2} \mathrm{Y}$ todos sin excepción, en mayor o menor medida, han empezado a merecer atención por parte de la historiografía reciente (Robes Sierra 1992; Callado Estela 2014a; 2015).

Parece llegada la hora, pues, de rescatar también del olvido al resto de cenobios que las hijas de santo Domingo levantaron a lo largo y ancho del levante peninsular. Lo pretenden las páginas que siguen. En concreto con el de Corpus Christi de la localidad valenciana de Carcaixent, en la ribera del rio Xúquer. Fundación tardobarroca ésta objeto en el Setecientos del interés histórico de uno

1 Un repaso sobre el estado de la cuestión de los claustros femeninos, en la España Moderna y para las distintas órdenes religiosas, en Reder Gadow (2000). Más recientes son las aportacione recogidas en Campos y Fernández de Sevilla (2004 y 2011) y Viforcos Marinas (2000 y 2005).

2 El caso de Santa María Magdalena (Beaumont de Navarra 1725). O el de Nuestra Señora de Belén, sobre el que escribió una Historia - perdida quizá para siempre- el historiador dominico Teixidor (1895: II, 246).

SCRIPTA, Revista internacional de literatura i cultura medieval i moderna, núm. 8 / desembre 2016 / pp. 224-240 ISSN: 2340-4841 · doi:10.7203/SCRIPTA.8.9296 
de sus primeros confesores. Hablamos de fray José Agramunt, autor del inédito Parayso de Dios. Idea del religiosíssimo monasterio de señoras dominicas de la real villa de Carcaxente. ${ }^{3}$

\section{Mujeres, reforma y resistencia}

Fueron los albores de la Modernidad momentos de renovación para la Iglesia universal vividos de manera intensa por la orden de Predicadores, en la Monarquía Hispánica y muy particularmente en la Provincia de Aragón, muchos de cuyos conventos, superada la claustra bajomedieval, se debatieron durante décadas entre la adopción de la reforma, auspiciada por la corona y la Santa Sede y con la colaboración de las autoridades dominicanas, y la resistencia a la misma, fuera por parte de individuos particulares o la totalidad de la comunidad. ${ }^{4}$

Especialmente revueltos iban a mostrarse determinados establecimientos femeninos. Porque ni los vínculos de tales con algunos de los estandartes masculinos del aggiornamento blanquinegro, ni la presencia entre sus monjas de mujeres ejemplares, promotoras de nuevos cenobios observantes, garantizaron el triunfo definitivo de la susodicha reforma, todavía contestada en vísperas de las Luces pese al silencio impuesto a este respecto por la historia oficial de la orden. Conocidos resultan los casos de Montesión de Barcelona (Garganta 1965: II, 643-645) o Santa María Magdalena de Valencia, origen este último - tan sólo en el Seiscientos- de media docena de fundaciones monjiles repartidas por toda la Provincia (Callado Estela 2014a). Tres de ellas, incluidas la que ahora nos ocupa, se debieron a la venerable madre sor Inés del Espíritu Santo, en el siglo Sisternes de Oblites, sin duda la más célebre dominica valenciana de todos los tiempos. ${ }^{5}$ Había venido al mundo allá por 1612 en la Casa de tales apellidos, ambos de rancio abolengo, dedicados hacía tiempo a la administración de justicia desde sus más altas responsabilidades y vinculados a la orden militar de Montesa (Canet Aparisi 1990; Gómez Orts 2011: 511-527; Cerdá Ballester 2012: 338). Huérfana a los ocho años, con apenas once y en compañía de su hermana Ángela ingresó en el convento de las magdalenas, donde profesaría solemnemente el 23 de enero de 1629. Entregada desde entonces a la más estricta observancia de la regla, cuestionada por buena parte de aquella comunidad, sor Inés se granjeó extraordinario crédito entre algunas jóvenes correligionarias, como la madre Juliana Ximeno. ${ }^{6}$ A ella participaría sor Inés

3 Localizado casualmente en el Archivo del Convento de la Inmaculada Concepción de Torrent [=ACICT] con ocasión de la elaboración de nuestro estudio más arriba citado sobre las monjas belemitas de Valencia. A su priora debemos las facilidades brindadas para su consulta y análisis.

4 Véase, sobre este tema, Beltrán de Heredia (1939: 185-217 y 1941), Garganta (1957: 98-121) y Robles Sierra (1983: 183-210).

5 Su biografía es bien conocida, gracias a Beaumont de Navarra (1725: 215-320), Sempere (1903) y Callado Estela (2014b: 123-182)

6 Nacida en Morella, «a 10 de ma[i]g entrà relixosa sor sor [sic] Juliana Gimeno, de edat de digüit anys [...] a[n]y 1623» con el nombre de sor Juliana de la Santísima Trinidad. Archivo del Real Convento de Santa Catalina de Siena[=ARCSCS]. Fondo Magdalenas. Libro antiguo de la fundación y privilegios del convento de Santa María Magdalena y ingresos de religiosas: 48bis. Una breve reseña biográfica en ACICT. Fondo Corpus Christi de Carcaixent. J. Agramunt, Parayso de Dios...: 8-9v.

SCRIPTA, Revista internacional de literatura i cultura medieval i moderna, núm. 8 / desembre 2016 / pp. 224-240 ISSN: 2340-4841 · doi:10.7203/SCRIPTA.8.9296 
su idea de erigir un nuevo convento que recuperase los rigores de la regla primitiva, sin las dispensas ni concesiones que se arrogaban las habitadoras de Santa María Magdalena. Fue así como en 1639 las dos monjas, en compañía de las madres Ángela Sisternes de Oblites y Luisa Aguilera y bajo el patronazgo del teólogo vilarealense Juan Gil Trullench, partieron hacia la población natal de éste para fundar allí el monasterio pretendido bajo la advocación de Corpus Christi (Beaumont de Navarra 1725: 237-238). ${ }^{7}$

En breve lograron las cuatro monjas hacer de tal establecimiento un baluarte observante. Así permanecería al menos durante los quince años en que formaran parte de su comunidad. Hasta que una revelación acaecida a la fundadora mientras oraba en el coro marcara el destino de las religiosas. Conforme a la tradición, habría ocurrido todo cuando:

Estando [...] un día en oración en el convento de Villareal la reveló [Dios] ser de su gusto fundara otro convento en que plantasse la misma observancia, de la que avía de ser exemplar y norma, cuyos buelos siguirían muchos espíritus de su agrado. Manifestole avía de ser en la villa de Carcaxente, noble población de este reyno, y que su poder abriría camino a tan alta empressa (Beaumont de Navarra 1725: 246)

Animada por el Provincial de Aragón fray Francisco Crespí de Valldaura, ${ }^{8}$ contaría esta vez la madre Inés Sisternes de Oblites con el respaldo de su confesor, el padre Francisco Faxardo, ${ }^{9}$ y su primo, el canónigo de la catedral de Valencia don Jerónimo Pujasons Sisternes. ${ }^{10}$ El proyecto, con las correspondientes licencias de la orden y el mismo diocesano, terminó siendo patrocinado por su propia tía doña Sabina Sisternes de Oblites y Centoll, hija del que fuera regente del Consejo de Aragón. ${ }^{11}$ Viuda ya por entonces de don Vicente Sisternes Descals y muertos los diez hijos con él habidos, ${ }^{12}$ pretendía ésta destinar su hacienda a la creación de un claustro femenino, inicialmente

7 Todavía por estudiar, pueden verse algunos detalles sobre el mismo en 1879. Apuntes históricos de Villareal: 493 y ss.; Nebot Climent, L. Apuntes históricos de Villareal: 166 y ss.; y Martí Cercós, P. Apuntes históricos de Villareal: I, s. p. Manuscritos los tres conservados en el Archivo Municipal de esta localidad.

8 De la saga valenciana de los Crespí, fray Francisco había sido con anterioridad prior del convento de Predicadores del cap $i$ casal. En 1654 ingresaba en el episcopado como obispo de Vic, falleciendo en esta sede, en 1662, a los sesenta años de edad. Callado Estela (2007: 305-319).

9 Dominico murciano de la casa de los Vélez y profeso en el valentino convento de Predicadores, de donde se trasladó a San Esteban de Salamanca para Teología, en que se le otorgaría el magisterio poco antes de convertirse en regente de la Minerva romana. A su regreso a Valencia tuvo una notable proyección académica a través del Estudi General, en el que regentó una cátedra de Teología. Biblioteca Universitaria de Valencia [=BUV]. Ms. 149, J. Agramunt, Elpalacio real de la sabiduría. Idea del convento de Predicadores de Valencia. Tomo tercero en que se trata de los obispos, prelados, inquisidores, confessores de reyes, cathedráticos y escritores hijos de este real convento, 155 y 318.

10 Hijo con toda probabilidad de don Vicente Pujasons y doña Francisca Sisternes de Oblites y Centoll, formaba parte del cabildo metropolitano desde 1642, gozando a partir de entonces de gran influencia entre los prebendados de la catedral, quienes confiaron en él como vicario general de la sede vacante en 1649. Falleció a finales de 1653. Callado Estela (2011).

11 No otro que don Melchor Sisternes de Oblites y Centoll, señor de Benillup y jurista de dilatada trayectoria. Gómez Orts (2012: 1567-1579).

12 Todo hace indicar que la numerosa prole de doña Sabina habría desaparecido ya en 1652, fecha en que solicitó al Consejo de Aragón que «la pensión que se concedió para uno de sus hijos, pueda gozarla ella por habérsele muerto todos». Archivo de la Corona de Aragón [=ACA]. Consejo de Aragón. Leg. 896, doc. 201.

SCRIPTA, Revista internacional de literatura i cultura medieval i moderna, núm. 8 / desembre 2016 / pp. 224-240 ISSN: 2340-4841 · doi:10.7203/SCRIPTA.8.9296 
en Valencia y junto al cementerio donde reposaban las víctimas de la pasada peste que entre 1648 y 1649 había diezmado la capital del Reino (Gavaldá 1651). Según la misma interesada,

$[\ldots]$ porque las almas de muchos que estavan allí enterrados y padecían gravísimas penas en el Purgatorio avían de ser aliviadas por los sufragios que en él ofrecerían a Dios sus esposas « (Beaumont de Navarra 1725: 246)

Como quiera que fuese, la fundación se alzaría al final en la villa de Carcaixent.

\section{En carcaixent y de Corpus Christi}

El 13 de abril de 1654, aquel año festividad de san Vicente Ferrer, llegaba a Carcaixent sor Inés Sisternes de Oblites en compañía de las madres Juliana Ximeno, a la que llevó consigo como priora del nuevo cenobio, y Juana del Rosario, hija del convento de Santa Ana de Murcia, reservando para sí el cuidado de las futuras novicias. Arribaron con ellas dos virtuosas monjas más procedentes de Vila-real, sor Potenciana de la Concepción, de la que casi nada se sabe, ${ }^{13}$ y sor Teresa de San Vicente. ${ }^{14}$ Las cinco en aclamación de multitudes, según la crónica oficial conventual:

Asistieron aquella tarde [...] a las Vísperas solemnes en la parroquia y a la processión que en esta villa se haze al Ángel del Apocalypsi san Vizente, a quien professan suma entrañable devoción. Y concluhidas las funciones acompañaron con processión a las dichas señoras asta su encierro, que estava ya dispuesto y adornado con las riquíssimas alhajas de una suma pobreza. Atendíalas el respeto común como si fueren unos ángeles baxados del Cielo para el consuelo de esta tierra, venerándolas todos a medida de lo mucho que ligera la fama avía ya pregonado de sus grandes virtudes. $^{15}$

Desde aquel día quedó este establecimiento religioso - como el de Vila-real - comprometido con la observancia, a decir de sus primeros confesores:

Aquí se guardan las constituciones de la orden con la mayor puntualidad. La assistencia en el coro es admirable, siendo los Maytines a medianoche indeficientes y las demás horas canónicas a su tiempo con la más plausible devoción. El retiro que se professa no cabe en ponderación, pues negadas a los ojos del mundo, cada una es una Sara, que velado el rostro sólo al Divino Esposo se descubre. No hablaré de los exercicios voluntarios, por no ofender la gran modestia de tan venerables señoras, que emulándose unas a otras sagradamente las virtudes, estudian con humilde santa ambición exederse en perfección, rigores y penitencia. ${ }^{16}$

13 Salvo que en 1679 sería priora de Corpus Christi de Carcaixent.

14 En el siglo Vicenta Ribera y de las primeras religiosas en profesar allí. Lo había hecho a la tardía edad de veinticinco años, Ello no le impidió destacar pronto por su estricta vida observante, «por esso la mandaron venir a este santo convento de Carcaxente por una de sus $[\ldots]$ fundadoras, siendo assí que sólos tenía treynta y dos años de edad, pero en ellos peinava muchas canas de virtud». Llegaría a ser maestra de novicias y varias veces priora de este nuevo convento, donde falleció en agosto de 1675. La biografía de la madre Ribera en ACICT. Fondo Corpus Christi de Carcaixent. Agramunt, J. Parayso de Dios . ..: 22-24v.

15 Ibidem: 3

16 Ibid.

SCRIPTA, Revista internacional de literatura i cultura medieval i moderna, núm. 8 / desembre 2016 / pp. 224-240 
Estrictas prácticas en el vestido, el ayuno, la oración, el silencio o el aislamiento del exterior igualmente constatadas por posteriores testimonios:

[...] las religiosas visten ropa de lana al interior y al exterior; el hábito es de estameña muy blanca, pero de más baja calidad, más basta y de menos valor que la generalmente usada en la mayoría de los conventos de la orden. Se ayuna desde el 14 de septiembre hasta el día de Resurrección, fuera de los domingos. También se ayuna todos los viernes del año, los días de Témporas y Rogaciones y las vigilias de san Juan Bautista, san Pedro, Santiago, nuestro padre santo Domingo, san Lorenzo Mártir, Asunción de Nuestra Señora, san Bartolomé y Natividad de la Santísima Virgen. La comida es siempre de vigilia, sin comer nunca carne ni viandas guisadas con ella, fuera de las religiosas enfermas y en la enfermería. Los maytines se rezan a medianoche. Todos los días se tienen dos horas de oración mental en común. El silencio es rigurosísimo, la abstracción del mundo extremada, hasta el punto de no haber en todo el convento sino un solo torno para todo el servicio de la casa, inclusive el de la sacristía, y un solo locutorio pobrísimo y pequeño. Las religiosas únicamente reciben visitas tres o cuatro veses al año, sin admitirse más, aunque sean de su familia, fuera del caso de grave necesidad, urgencia o servicio del Señor (Sempere 1903: 46-47)

Poco trascendería, sin embargo, a propósito del entorpecimiento que para los planes fundacionales de la madre Sisternes de Oblites y sus monjas supuso la oposición inicial que tal asentamiento suscitaba entre algunos vecinos, habitual por lo demás en estos casos (Atienza López 2008). La historia oficial dominicana pasó de puntillas por este episodio, despachándolo con un lacónico comentario:

[...] el Demonio, que presentía la guerra a muerte que se le iba a hacer en Cargagente por las esposas del Crucificado, sugestionó a muchos vecinos de esta villa para que, obstinadamente, impidieran la ida allí de las religiosas dominicas [...]. [Pero] los alborotos ocasionados por los hijos de las Tinieblas fueron apaciguados con facilidad y todos los ánimos quedaron quietos, calmados y contentos (Sempere 1903: 57)

Tendríamos que recurrir a los historiadores locales para tratar de aclarar lo sucedido. En opinión de éstos, la cofradía del Rosario que debía albergar el convento -según lo establecido por antiguas disposiciones pontificias- pudo estar en los orígenes de semejante rechazo:

A tal fundación se opuso, en un principio, la villa ante el temor de que desapareciera de la parroquia la cofradía del Rosario, que por aquel entonces se hallaba en un estado muy floreciente. Pero habiéndose acordado que dicha cofradía sería respetada en el punto donde radicaba, además de que la comunidad se obligaría a admitir perpetuamente dos religiosas de coro, con dote de 400 libras, se desvaneció toda dificultad y la obra comenzó (Fogués Juan 1934: 77-78)

Las mismas fuentes ofrecen otros detalles acerca de la localización de las dominicas junto al antiguo Hospital de Carcaixent, conforme a los deseos de su principal benefactora doña Sabina de Sisternes y Centoll y algunas donaciones particulares más:

[...] aceptaron las religiosas la donación de una casa y corral que les hiciera una dama carcagentina, llamada Úrsula Casanoves, casa que estaba situada en el punto donde se halla actualmente la portería del monasterio. Pero como con este patio no tuvieron lo suficiente para el emplazamiento del edificio, consiguieron de la Villa que les cediera el Hospital de peregrinos con su cementerio, situado en la esquina de la calle del Párroco Monzó, obligándose ellas por 
su parte a adquirir un edificio para trasladar a él este establecimiento benéfico. Con este objeto, compraron al Clero una casa en la calle de San Cristóbal, a espaldas del monasterio, adonde se trasladó más tarde dicho Hospital (Fogués Juan 1934: 79). ${ }^{17}$

En aquel lugar concreto se erigió el cenobio, también dedicado a Cristo Sacramentado y que, a partir de 1657, fallecida su primera superiora sor Juliana Ximeno, gobernaría la madre Sisternes de Oblites. ${ }^{18}$ Tiempos de perfeccionamiento de la fábrica conventual. ${ }^{19}$ Pero también de crecimiento de la incipiente comunidad, bajo la supervisión de su primer vicario, el padre Faxardo, y a partir de nuevas vocaciones religiosas, procedentes en su mayoría de la misma población y alrededores y atraídas por la fama y el modelo de vida observante impulsado por la más célebre de sus inquilinas. Sumaríase a las citadas doña Sabina Sisternes de Oblites y Centoll, retirada finalmente del mundo en este claustro, al que donó su hacienda -valorada en diez mil ducados- poco antes de profesar en el mismo como sor Sabina del Santísimo Sacramento. Dice así la crónica conventual:

[...] murieron los diez hijos y viéndose doña Sabina frustrada de todos los gozos del mundo, tiró las cortinas al mejor conocimiento entregándose toda a las cosas permanentes de la gloria. Emprendió con su sobrina [...] la fundación de este santo convento, según queda dicho el día 13 de abril del año 1654. Esse mismo día se encerró con las religiosas doña Sabina, vestida de secular, con breve del nuncio. Y a poco más de un año, se vistió el santo ábito por devoción, asta que lo tomó solemnemente el día 20 de agosto del año 1656, siendo de edad de 59 años; y passado el año del noviciado, hizo professión a 4 de octubre $1657 .{ }^{20}$

Desde aquel día tía y sobrina trabajarían duramente por la consolidación de la comunidad, compatibilizando la vida observante con el trabajo manual que garantizase su sustento, porque

Fue esta comunidad muy pobre en un principio, ya que había de dedicarse, para atender a su sustento, a la industria de la seda, a la fabricación de tejidos para lo que tenían un telar, a la

17 Algo diferente resulta la interpretación de los hechos proporcionada por P. Sucias y Aparicio. En sus inéditas Notas útiles para la Historia del reino de Valencia -conservadas en la Biblioteca Municipal de Valencia- hablaría así de los orígenes de este establecimiento: «Los justicias y jurados de la villa de Carcagente deseaban hacer un convento de religiosas, pues ya tenían el de los padres franciscanos descalzos; y al que quisiese hacerlo daban una porción de terreno que había servido en tiempos anteriores de cementerio de apestados, por la peste bubónica del año 1648. Sabedora de todo esto sor Inés Cisternes, religiosa dominica del convento de las Magdalenas de Valencia, dio comienzo a las gestiones para la fundación y pasó a la villa de Carcagente e indagó todo lo necesario. En breve tiempo sacó todas las licencias para poder hacer la fundación».

18 «Murió la venerable madre sor Juliana antes de concluir su priorato el día 23 de enero del año 1657, causando su muerte general llanto en toda la villa y amargo sentimiento en sus hijas. Passó de esta vida a la eterna a los 51 años de su edad». ACICT. Fondo Corpus Christi de Carcaixent. Agramunt, J. Parayso de Dios...: 9v.

19 El templo no quedaría finalizado hasta 1689. Constituye ahora el único vestigio del conjunto cenobial, transformado en Auditorio Municipal. Véanse Sanchis Sivera (1922: 175), Gimeno. Tormo (1923), Orellana (1930: 108) y Moreno Burriel (1990).

20 ACICT. Fondo Corpus Christi de Carcaixent. Agramunt, J. El Parayso de Dios...: 21. La importancia en el seno de la clausura de los vínculos entre tías y sobrinas ha sido puesta de relieve por Poutrin (1995: 34, 42, 84). 
confección de medias de hilo y fabricar perfumes, de los que se usaban en las iglesias con motivo de las solemnidades (Fogués 1934: 79-80). ${ }^{21}$

Una década después de su llegada a Carcaixent la madre Inés Sisternes de Oblites abandonaba el convento de Corpus Christi para seguir su periplo fundacional - con la erección de Nuestra Señora de Belén, en la capital - hasta el mismo día de su muerte, sobrevenida al poco tiempo. Dejó la tutela del lugar en manos de su tía sor Sabina, hasta entonces tornera, portera, procuradora y sub-priora del mismo. Muy a pesar de la interesada, por lo que parece,

[...] pues Nuestro Señor la absolbió luego del oficio, descargándola de la cruz de la prelacía.

Dos meses governó el convento, con gran satisfación y observancia, al cabo de los quales le dio una enfermedad de ardientes calenturas y dolores, que la llevó a los extremos de la vida. ${ }^{22}$

La muerte de la religiosa, el día de Navidad de 1672, cerró la etapa fundacional propiamente dicha de este cenobio. ${ }^{23}$ De la reconstrucción histórica de aquellos años, quienes lo protagonizaron y la generación inmediatamente posterior se ocuparía, antes de finalizar la centuria, el dominico fray José Agramunt. ${ }^{24}$

\section{El parayso de dios}

El padre José Agramunt ${ }^{25}$ había nacido en Valencia el 12 de noviembre de 1657. Su temprana vocación religiosa le llevó a vestir el hábito blanquinegro en el convento de Predicadores de la misma ciudad, con

21 Según este autor, «en el siglo XVIII consiguieron ya una posición más holgada, pues llegaron a amortizar un capital de 18.000 libras. Pero más tarde, con motivo de los crecientes impuestos, con el saqueo de los franceses y con la ley de la desamortización, finalmente, vinieron a quedar en la mayor indigencia»».

22 ACICT. Fondo Corpus Christi de Carcaixent. Agramunt, J. Parayso de Dios...: 23.

23 Los elogios fúnebres hacia la finada se hicieron hueco en las actas del capítulo provincial celebrado dos años más tarde. 1674. Acta capituli provincialis celebrati Caesaraugustae, in regali Praedicatorum conventu, die 14 aprilis, anni 1674: 20 - 21. Zaragoza. A su desaparición seguiria un ruidoso pleito entre la comunidad de Corpus Christi con don Juan Sisternes de Oblites, a raíz de las cuatro mil libras con que la difunta había dotado este convento. AHN. Nobleza. Almodóvar. C 26, D 21.

24 A quien algunos confunden con otro fray Domingo Agramunt, «natural de la ciudad de Valencia, del antiguo linage de Agramunt, apellido de unos cavalleros de Navarra que baxaron en servicio del rey de Aragón a la conquista de Valencia [...]. Tomó el hábito en Predicadores de Valencia por los tiempos de san Vicente Ferrer, y ambos fueron no sólo contemporáneos, sino también condiscípulos [...]. Floreció tan admirablemente en las letras que mereció ser admitido al grado de dotor en la célebre Universidad de París. Manifestó su sabiduría en la cátedra, regentando la de Prima de Teología en la Universidad de Lérida [...]. Fue quatro vezes prior de su convento». Lo hace Rodríguez 1747: 113). Tampoco debe identificársele con el dietarista José Agramunt, este sí coetáneo y más conocido por su obra Libro de casos sucedidos en la ciudad de Valencia, que editaron Callado Estela y Esponera Cerdán (2004: 91-178).

25 El mejor biógrafo del dominico Teixidor, J. Necrologio de este real convento de Predicadores de Valencia. Devidas memorias a sus hijos nativos con extensión en los más ilustres recogidas de monumentos antiguos y fidedignos. Tomo 4. Contiene los difuntos desde el año 1478 hasta 1775, pp. 340-345, en Biblioteca Universitaria de Valencia [=BUV]. Ms. 933. Fue seguido -casi literalmente y con graves errores de interpretación- por Fuentes (1930: 21 - 26). Véase también Ximeno (1749: 234-235).

SCRIPTA, Revista internacional de literatura i cultura medieval i moderna, núm. 8 / desembre 2016 / pp. 224-240 ISSN: 2340-4841 · doi:10.7203/SCRIPTA.8.9296 
fecha 19 de septiembre de 1672, haciendo solemne profesión el 21 de noviembre del año siguiente. Estudió Artes, Teología y Hebreo. Hebreo, precisamente, empezaría a enseñar a novicios y frailes dentro de los planes de formación establecidos por la orden de santo Domingo, todavía con relativo protagonismo para las lenguas (Cortabarria Beitia 1970: 79-127 y 359-392). En ello anduvo hasta que en 1691 acompañara a Mallorca a su nuevo virrey, el valenciano don José de Castellví y Alagón, conde de Cervellón y marqués de Villatorcas, como confesor personal y maestro de su numerosa prole. ${ }^{26}$

La carrera académica del religioso proseguiría en aquella isla, más allá de su principal ocupación y el desempeño de algún oficio eclesiástico, como el de examinador sinodal (Ximeno 1749: 234). Le bastaron así unos meses para hacerse con una cátedra de Hebrero instituida en la Universidad insular por las autoridades de la misma. ${ }^{27}$ Pudo ocupar otras con posterioridad, según las notas autobiográficas manejadas por sus hermanos de hábito. Concretamente de Filosofía, en 1695, coincidiendo con su reconocimiento como presentado por parte del Maestro general de la orden fray Antonino Cloche; ${ }^{28}$ y de Teología, un trienio más tarde. ${ }^{29}$

Todo hace pensar que antes de concluir la centuria fray José habría regresado ya definitivamente a la Península. ${ }^{30}$ Aquí le sorprendió el estallido de la Guerra de Sucesión, con notable impacto entre el clero valenciano en general y los hijos del Patriarca de Caleruega en particular (Pérez Aparicio 1978: 251-252 y 261). Las simpatías del dominico por el bando borbónico acabaron con su reclusión en la celda conventual, por espacio de varias semanas, así como un breve destierro, durante el dominio austracista de la capital valentina. Concluida ésta, la fidelidad demostrada hacia Felipe V estuvo detrás de su nombramiento como predicador real el 16 de febrero de 1708 -ya lo era de la orden desde comienzos de siglo- ${ }^{31}$ y un año y cuatro días después catedrático de Hebreo del Estudi general valentino, ${ }^{32}$ por comisión y en sustitución de su hermano de hábito el padre Vicente Blanes, hacía

26 A propósito de tal linaje, véanse los trabajos de Felipo Orts (2002; 2007a: 97-121; 2007b).

27 El 7 de mayo de 1792. Agradecemos el dato al Profesor R. Ramis Barceló. Sobre el particular, su trabajo junto a Cassanyes Roig (2014: 8)

28 «El reverendísimo Cloche, General, le nombró de presentado de gracia con su patente, firmada en Roma a 13 de febrero de 1695, que por ciertos motivos no admitió y renunció humildemente en manos del mismo padre reverendísimo». Fray Antonino lo intentaría años después, «y le hizo presentado del número [...] con su patente de 29 de junio 1706». BUV. Ms. 933, Teixidor, J. Necrologio..., p. 340.

$29 \mathrm{El} 12$ de mayo de 1698. Ibíd..

30 Lo había hecho ya con anterioridad de manera intermitente. Por ejemplo, en mayo de 1697 solicitó a los responsables académicos mallorquines dejar la cátedra y trasladarse a Xàtiva para impartir allí un curso de Artes.

31 Con patente firmada en Nápoles por el Maestro general Cloche el 25 de mayo de 1701. BUV. Ms. 933, Teixidor, J. Necrologio..., 340.

32 Es decir, el 20 de febrero de 1709. Ibíd.

SCRIPTA, Revista internacional de literatura i cultura medieval i moderna, núm. 8 / desembre 2016 / pp. 224-240 ISSN: 2340-4841 · doi:10.7203/SCRIPTA.8.9296 
poco fallecido (Felipo Orts 1991: 308). Su plaza en esta universidad salió a concurso en diciembre de $1721 .^{33}$ Aunque recaería en el religioso mínimo de origen francés fray Alexandro Brehón. ${ }^{34}$ No obstante ello, «en atención a las prendas y desempeño de Agramunt en el concurso, le nombraron cathedrático extraordinario de Lengua Santa con 25 libras de salario al año». ${ }^{35}$

En la cátedra y el púlpito, pues, con aplaudidas predicaciones durante las Cuaresmas de aquel tiempo, ocuparía fray José el resto de sus días. Así le sorprendió la muerte el 12 de enero de 1732, a los setenta y cinco años de edad y en el convento de Predicadores de Valencia. Dejaba un legado literario de amplia temática, fruto ni más ni menos de tan dilatada labor docente y homilética. ${ }^{36}$ Obras teológicodevocionales, vinculadas sobre todo al misterio del Rosario, del que siempre fue activo militante muestro religioso, o al culto a Raimundo de Peñafort, cuya hermandad él mismo había constituido en su cenobio natal. Manuales de gramática hebraica, como no podía ser de otro modo tras una vida a ella consagrada. Y escritos de carácter más histórico, relacionados con la orden de Predicadores, algunos de sus santos, beatos y venerables -Luis Bertrán y José Bono, sin ir más lejos-y determinados establecimientos religiosos. Al primero de la capital del Turia dedicó su Palacio real de la sabiduría. Idea del convento de Predicadores de Valencia, que mereció las críticas del historiador dominico Teixidor:

A los que leyeren los manuscritos de Agramunt prevengo sea con cautela, porque aunque su intención fue recta se dejó llevar nimiamente del afecto de llenar este real convento de gloria que él imaginó como si las verdaderas que tiene no fueran superabundantes para hacerle

33 Realizando el correspondiente examen el día veintisiete, en que «leyó este opositor la hora que le tocó a los veinte y quatro de la Sagrada Biblia Hebrea, del capítulo veinte y dos de Josué, que empieza en hebreo azy querah y en latín et advocavit, y se acaba vengam y en latín et filii etiam, que fue el primero que eligió de los tres que se le picaron en presencia del señor rector, syndico, procurador general, abogados y pavordres». Archivo de la Universidad de Valencia [=AUV]. Libro 470, Oposiciones a cátedra 1720 a 1751: 53v.

34 Era exactamente «lector jubilado y asistente general por la nación de Francia en la religión de mínimos de san Francisco de Paula». Ibídem: 54. Confirma su toma de posesión Albiñana Huerta (1998).

35 BUV. Ms. 933, Teixidor, J. Necrologio..., 341.

36 Entre los títulos impresos, por orden cronológico, Devoción del Santíssimo Rosario y modo de contemplar sus misterios con exemplos y favores que la Virgen ha hecho a sus devotos y las estaciones a la via crucis con otras devociones, Barcelona, 1689, y Valencia, 1690 y 1695; Flor y fruto del más sagrado rosal. Dividese en tres partes. En la primera, se ponen las flores y rosas del Santíssimo Rosario con las meditaciones de sus divinos misterios. En la segunda, los frutos de las grandes indulgencias que gozan sus cofadres, confirmadas por nuestro muy santo padre Inocencio XI, año 1679. En la tercera, se añaden algunas questiones morales y curiosas para cabal inteligencia de esta obra, Mallorca, 1694, y Valencia, 1694; Los tres estados del sol. Discurso panegirico en la solemne translación de la imagen del santo Christo de la ciudad de Alcúdia en Mallorca, Mallorca, 1697; Constituciones de la hermandad de san Raymundo de Peñafort, sita en el real convento de Predicadores de Valencia, Valencia, 1704; y Nuevos frutos del Rosario. Indulgencias y otras gracias concedidas por nuestro santíssimo padre Benedicto XIII en los tres primeros años de su pontificado. Addición con notas y reflexiones al libro intitulado Flor y fruto del más sagrado rosal, Valencia, 1727. Ximeno (1747: 234 - 235). En cuanto a los manuscritos, en su mayoría no localizados, Vita sanctissimi Ludovici Bertrandi, Valentina confessoris sacri ordinis Praedicatorum (1679); Brevis enodatio gramaticen sacrosanctae linguae hebraicae (1680); Dedicatoria a santo Thomás de Aquino de un sermón que a la celebridad de su cíngulo predicó en nuestro convento de Mallorca el padre fray Francisco de Mallorca, capuchino (1697); y Compendio de la vida y virtudes del venerable padre fray José Bono. BUV. Ms. 933, Teixidor, J. Necrologio...: 343-345. 
celebérrimo, como lo es en todo el orbe $[. ..] .^{37}$

Ni una sola censura del susodicho tuvo la otra gran historia conventual del padre Agramunt Parayso de Dios. Idea del religiosíssimo monasterio de señoras dominicas de la real villa de Carcaxente, concluida el año 1701 en su condición de vicario y confesor de aquella comunidad. La componían entonces veinticinco religiosas de coro, con los votos de pobreza, castidad y obediencia y la obligación de acudir al rezo coral de las horas canónicas, el oficio de la Virgen y la oración mental; y otras nueve de la obediencia, con idénticos votos a los de las primeras, pero sin deber de asistir a las plegarias comunitarias y ocupadas más en las labores domésticas del cenobio.

Desde tiempo inveterado las autoridades dominicanas venían insistiendo en la importancia de preservar para la posteridad la memoria de la orden. ${ }^{38}$ Con escaso éxito y hasta la misma actualidad, a juzgar por las palabras de fray José Agramunt en la advertencia preliminar a su obra, elaborada según él mismo a partir de la recopilación de documentos, noticias y testimonios de las propias monjas:

La omissa negligencia que acostumbra tener nuestra religión en poner en memoria las cosas individuales de los sujetos insignes se ha participado herencia de siglo en siglo, trascendiendo hasta el claustro más moderno. Este lastimoso motivo ocasiona que las noticias que escrivo en estas páginas no sean tan singulares como yo quisiera y fuera menester para todo. Y para que del todo no perescan tan venerables recuerdos, me hallo prechado a escribir con la generalidad de noticias que el largo tiempo y la corta memoria dieren licencia y permisso. ${ }^{39}$

No obstante, la historia blanquinegra en términos generales, como la de este convento especialmente, trascendía el simple eruditismo. Porque encerraba además los mejores modelos de vida para las nuevas generaciones de religiosos y religiosas. Ambas pretensiones estarían en la base del escrito que ahora nos ocupa, más la segunda que la primera, reconoce su autor:

Contiene el libro, muy reverendas madres y señoras mías, entre las breves memorias de la fundación de esse santo convento los dulzes recuerdos de muchas de sus religiosas, que concluydos los términos de esta perecedera vida caminaron por las sendas de la eternidad [...]. ${ }^{40}$

A lo largo de doscientas páginas se haría presente, por tanto, no tanto el historiador de la fundación - con apenas unas líneas para el caso $-{ }^{41}$ como su director espiritual, sobre el que recaía una gran responsabilidad en la gobernanza de tal claustro. Como tal, el padre Agramunt debía ofrecer a las dominicas carcagentinas de Corpus Christi un espejo de virtudes en el que mirarse. Ninguno mejor que el de aquellas hermanas fallecidas en olor de santidad desde su apertura:

Todo el libro es un delicioso jardín de fragantes bellezas, un ameno parayso de florecientes

37 BUV. Ms. 933, Teixidor, J. Necrologio ...: 345.

38 Véase sobre el particular Beltrán de Heredia (1965), Esponera Cerdán (2003) y Callado Estela (2012).

39 ACICT. Fondo Corpus Christi de Carcaixent. Agramunt, J. Parayso de Dios...: Advertencia, s. f.

40 Ibidem, [Introducción]: s.p.

41 Ibidem, Fundación: 3-7.

SCRIPTA, Revista internacional de literatura i cultura medieval i moderna, núm. 8 / desembre 2016 / pp. 224-240 ISSN: 2340-4841 · doi:10.7203/SCRIPTA.8.9296 
virtudes, un agraciado vergel de perfectíssimas flores, que sirviendo de glorioso ornato a la dominicana religión es deleytoso recreo del Cordero Imaculado Jesús ${ }^{42}$

Cada una de las biografiadas -hagiografiadas, si se prefiere- sería identificada en este sentido con una flor concreta, cuya suma alumbraría el odorífero vergel de ejemplaridad referido por fray José: ${ }^{43}$

\begin{tabular}{|l|l|l|}
\hline NOMBRE & FLOR & ÓBITO \\
\hline Juliana de la Santísima Trinidad, en el siglo Juliana Ximeno & Violeta & 23-I-1657 \\
\hline Raimunda de San José, en el siglo Josefa Pons & Nardo & 6-I-1661 \\
\hline Vicenta de la Ascensión, en el siglo Vicenta Gozalbo & Maravilla & 1-I-1662 \\
\hline María de los Angeles, en el siglo María Albelda & Flor de Adonis & 19-IV-1663 \\
\hline Francisca de los Reyes, en el siglo Francisca Amador & Azucena & 25-IX-1664 \\
\hline Esperanza de Jesús, en el siglo Esperanza Pauls & Amaranto & 10-II-1669 \\
\hline María de la Asunción, & Lirio & 16-III-1669 \\
\hline Josefa de Cristo, en el siglo Josefa Oliver & Maravilla de España & 31-IV-1670 \\
\hline Mariana de San José, en el siglo Mariana Navarro & Pomposa & 23-XII-1670 \\
\hline $\begin{array}{l}\text { Sabina del Santísimo Sacramento, en el siglo Sabina Sisternes de de } \\
\text { Oblites }\end{array}$ & Clavel & 25-XII-1672 \\
\hline Teresa de San Vicente Ferrer, Vicenta Ribera & Corona Imperial & 25-VIII-1675 \\
\hline Teodora de San Jacinto, en el siglo Teodora Ferrer & Jazmín & 23-XI-1675 \\
\hline Francisca de Jesús, en el siglo Francisca Bosch & Jacinto & 27-XII-1677 \\
\hline Agustina de San Nicolás, en el siglo Agustina Carrasco & Girasol & 7-VIII-1683 \\
\hline Juana de los Ángeles, en el siglo Angela Ferrer & Tulipán & 23-VI-1685 \\
\hline Tecla de Santa María, en el siglo Tecla Alminiana & Pasionera & 9-VIII-1699 \\
\hline \begin{tabular}{l} 
Hermenegilda de San Bernardo, Hermenegilda Jornet \\
\hline ACICT. Fondo Corpus Christi de Carcaixent. J. Agramunt, Parayso de Dios...
\end{tabular} & Rosa & 9-III-1701 \\
\hline
\end{tabular}

Diecisiete mujeres irrepetibles, acorde a los cánones de la época, con sus respectivas reseñas similares en estructura. Primero, los orígenes familiares de unas y otras, seguidos de los años de temprana vocación que las acompañaron hasta el abandono del siglo. Profesión religiosa y trayectoria comunitaria seguidamente. Y por último, enfermedad, muerte y fama de santidad. No

42 Ibidem, [Introducción]: s.p.

43 Cabe considerar los siguientes datos sobre Vicenta de la Ascensión, en el siglo Vicenta Gozalbo: Su fallecimiento fue recogido, junto al de una tal sor Clariana de los Ángeles, de la misma comunidad, en [1666] Acta capituli provincialis celebrati Barchinonae, in conventu Praedicatorum Sanctae Catherinae Martyris, die 25 aprilis 1665: 25. Respecto a Mariana de San José, en el siglo Mariana Navarro, se refiere a su desaparición en 1674. Acta capituli provincialis celebrati Caesaraugustae, in regali Praedicatorum conventu, die 14 aprilis, anni 1674...: 27. Finalmente, sobre Tecla de Santa María, en el siglo Tecla Alminiana, se debe tener en cuanta que de la muerte de esta religiosa -apellidada aquí de Jesús María- se habla en 1703. Acta capituli provincialis celebrati Valentiae, in regali Praedicatorum conventu, die 6 maii anno 1702: 31. 
todas las monjas, sin embargo, recibirían igual atención por parte del padre Agramunt. Las habría brevísimamente tratadas, en su mayoría. Frente a unas pocas - entre las que no se encuentran las religiosas fundadoras, a diferencia de lo acostumbrado en casos similares - abordadas in extenso. Biografías estas últimas con suficiente fuste para haberse materializado quizá de manera individual. Ocurriría con sor Agustina de San Nicolás (†1683) y sor Hermenegilda de San Bernardo $(\dagger 1701)$.

La primera dominica, más allá de los sacrificios, penitencias y éxtasis comunes a muchas hermanas, acogidas como las madres Teresa de San Vicente Ferrer o Tecla de Santa María a su magisterio espiritual, protagonizaría un combate con el Demonio tan cruento como dilatado en el tiempo. Excusa en manos de nuestro autor para recrearse en los distintos asaltos de tal cariz acontecidos casi a diario:

No contenta la rabia del Demonio de perseguir y afligir a la sierva de Dios, incitando y moviendo los ánimos contra ella, y escondiendo [...] la mano, pasó a perseguirla a lo descubierto, ya en los fuegos fantásticos y pavorosos [...], ya comoviéndole los humores, impidiéndole la respiración y moviéndole unos ahogos penossíssimos. Solíale dar este achaque quando estaba en recreación con las demás religiosas. Sentía mucho el Demonio que allí advertió de algunos defetos a algunas religiosas sus discípulas y en la educación espirituales hijas. Con que entendiendo la venerable Augustina era enfermedad natural, pedía licencia y se retirava a la celda, donde proseguía el Demonio en afligirla del mismo modo. Así también, si quería la sierva del Señor yr al coro, luego el Enemigo salía con semejantes embaraços para que las preladas no lo permitiesen. Con que la venerable madre, ya sabidora de que todo esto no era enfermedad de la naturaleza, sino traza del Demonio, la hubo de declarar y manifestar eran sólo tormentos del Enemigo y vivir advertida en adelante. ${ }^{44}$

Encuentros diabólicos, amén de otras indecibles maravillas, que los anteriores confesores de la comunidad, fray Juan Bautista Rodríguez y fray Lorenzo Gisbert, habían podido certificar ante las autoridades provinciales de la orden. ${ }^{45}$ Así lo corroboraría también el revuelo ocasionado en Carcaixent y alrededores a la muerte de sor Agustina:
Quedó su cuerpo hermoso, grave y alegre, pues aún con estar ajado a violencias de los accidentes, penitencias y trabaxos que le ocasionava el Enemigo común, parecía en la belleza un ángel y causava devoción sólo el mirarle. Clamorearon las campanas publicando su muerte y el pueblo redobló con sentimiento y alabanzas, pues en voz común se noticiavan unos a otros que era muerta una religiosa santa. Fue grande el concurso que acudió a ver y venerar aquel cuerpo [...]. Pedían unos con instancia algunas florecillas de las que adornaban el cadáver, anelavan muchos por alguna cosilla de su uso [...]. Desseavan por estremo muchos devotos se hiziessen celebrar devidas exequias a la venerable Augustina y ofrecían costear gustosamente las expensas. Dio también su palabra el venerable padre maestro fray Domingo Alegre de

\footnotetext{
44 ACICT. Fondo Corpus Christi de Carcaixent. Agramunt, J. Parayso de Dios..., Sor Augustina de San Nicolás. Capitulo $4^{\circ}$ Persigue el Demonio a la venerable Augustina: 34v. Hasta el capítulo provincial de 1684, que siguió a su muerte, llegarían los ecos de la cruzada de sor Agustina, a pesar de confundirle el nombre. 1684. Acta capituli provincialis celebrati Caesarangustae in regio Praedicatorum conventu, die 22 aprilis 1684: 36-37.
}

45 ACICT. Fondo Corpus Christi de Carcaixent. Agramunt, J. Parayso de Dios..., Sor Augustina de San Nicolás. Capitulo $8^{\circ}$ Encendida caridad y amor de Dios que tenía sor Augustina: 42 y ss. 
predicar las honras [...]. Pero todo lo desvió la humildad religiossíssima de este edificativo monasterio, con el pretexto de ser materia nunca parcticada en sus difuntas. ${ }^{46}$

Por su parte, la madre Hermenegilda de San Bernardo pareció mucho más inclinada a los ejercicios literarios. No en vano escribiría decenas de composiciones poéticas, como Al nacimiento de Christo Nuestro Señor, Vestido espiritual para el recién nacido Jesús, Vestido y adornos para el padre santo Domingo o A la Virgen cercana al parto. Poesías y opúsculos recopilados por obra y gracia del padre Agramunt, quien reconoció con cierto pesar:

Muchas otras poesías suyas havía. Pero andan tan divididas por varias partes que no es possible juntarlas. Otras [...], y no eran pocas, las quemó por su mano pocos días antes de morir [...]. Éstas que he escrito se conservaron a ocasión de tenerlas algunas religiosas. ${ }^{47}$

Por cierto que la desaparición de sor Hermenegilda daría pie a la repetición de escenas ya vividas entre los muros del convento de Corpus Christi de Carcaixent con ocasión del óbito de otras religiosas:

[...] se llenó toda la villa de la suavidad de su fama y olores de su santidad; y dexando los oficiales sus tareas, las mugeres sus ocupaciones domésticas, acudieron al convento a ver, y más a venerar, a aquella a quien por su retiro no conocían, a aquella a quien la suavidad de sus virtudes hizo famosa, no sólo en Carcaxente, sí también en todo el reyno y Provincia de la religión. ${ }^{48}$

Confiaba fray José Agramunt en dar pronto a la imprenta su Parayso de Dios. Es más, llegaría a incluir el protesto exigido al respecto por la Santa Sede - desde la reciente regulación canónica en materia de santos - a fin de evitar problemas a la publicación ${ }^{49}$. Con todo, esta obra - como tantos otros escritos de su autor - nunca vería la luz. Podría aventurarse que por el caos provocado en los claustros dominicanos a raíz de la inminente Guerra de Sucesión. Pero también debido a la actitud de la propia comunidad interesada, ya en forma de dejadez, ya de dificultad para afrontar los gastos una empresa editorial semejante. E incluso pudieron influir las rencillas del padre Agramunt con algunos hermanos de hábito de la escuela historiográfica del convento de Predicadores de Valencia, integrada por fray Jacinto Segura, fray Serafín Tomás Miquel o fray José Teixidor y cuyo mayor prestigio acabaría eclipsando su producción literaria (Esponera Cerdán 1996: 397-420).

46 Ibidem, Sor Augustina..., Capitulo 10 Dichosa muerte de la venerable sor Augustina: 50v-51.

47 Ibidem: 86.

48 Ibidem, Sor Hermenegilda... Cap. $11^{\circ}$ Dichosa muerte de la venerable madre sor Hermenegilda: $100 \mathrm{v}$. Un sucinto elogio de la difunta, «vitae exemplarissimae», le tributaría el capítulo provincial reunido un año después de su óbito. 1702. Acta capituli provincialis celebrati Valentiae, in regali Praedicatorum conventu, die 6 maii anno 1702...: 31.

49 Ibídem, Protestación: s.p. Al respecto del tema, no puede dejar de citarse el ya clásico estudio de Sánchez Lora (1998: 387 y ss). Más recientes y no menos interesantes resultan algunos de los trabajos incluidos en Vitse (2005).

SCRIPTA, Revista internacional de literatura i cultura medieval i moderna, núm. 8 / desembre 2016 / pp. 224-240 ISSN: 2340-4841 · doi:10.7203/SCRIPTA.8.9296 


\section{Bibliografía}

Alabrús Iglesias, R. Mª (2011) Tradición y modernidad. El pensamiento de los dominicos en la Corona de Aragón en los siglos XVII y XVIII, Madrid, Sílex.

—. (2012) La memoria escrita de los dominicos, Sant Cugat, Arpegio.

—. (2013) La vida y la sociabilidad de los dominicos, Sant Cugat, Arpegio.

Albiñana Huerta, S. (1988) La Universidad de Valencia y la Ilustración en el reinado de Carlos III. Valencia.

Amelang, J. et alii. (1990) Historia y género. Las mujeres en la Europa Moderna y Contemporánea, Valencia, Universitat de València.

Atienza López, A. (2008) Tiempos de conventos. Una historia social de las fundaciones en la España moderna, Madrid, Marcial Pons.

Beltrán de Heredia, V. (1939) Historia de la reforma de la Provincia de España (1450-1550), Roma, Institutum Historicum Ordinis Praedicatorum.

- (1941), Las corrientes de espiritualidad entre los dominicos de Castilla durante la primera mitad del siglo XVI, Salamanca, Dominicos Provincia de España.

- (1965) «Examen crítico de la historiografía dominicana en las Provincias de España y particularmente en Castilla», Archivum Fratrum Praedicatorum XXV, pp. 195 - 248.

Beaumont de Navarra, V. (1725) Compendio histórico del real convento de Santa María Madalena de religiosas del Gran Patriarca santo Domingo de la ciudad de Valencia. Ilustrado con las noticias de heroicas virtudes de algunas de sus hijas más insignes, Valencia, Juan González.

Cabanes Pecourt, Ma. D. (1974) Los monasterios valencianos. Su economía en el siglo XV. Valencia, Universitat de València. 2 vols.

Callado Estela, E. (2007) «Dominico, prior y obispo. Apuntes para una biografía de fray Francisco Crespí de Valldaura (1602-1662)», Anales Valentinos, 66, pp. 305-319.

—. (2011) Tiempos de incienso y pólvora. El arzobispo fray Pedro de Urbina, Valencia, Biblioteca Valenciana.

- (2014a) Mujeres en clausura. El convento de Santa María Magdalena de Valencia, Valencia, Universitat de València.

—. (2014b) «Sor Inés Sisternes de Oblites o la observancia dominicana», en E. Callado Estela (Coord.), Valencianos en la Historia de la Iglesia V, Valencia, Facultad de Teología "San Vicente Ferrer, pp. 123 - 182.

—. (2015) ElParaíso que no fue. El convento de Nuestra Señora de Belén de Valencia, Valencia, Universitat de València.

Callado Estela, E. \& Esponera Cerdán A. (2004) Memoria escrita, historia viva. Dos dietarios valencianos del Seiscientos, Valencia, Ayuntamiento de Valencia.

Campos y Fernández de Sevilla, M. J. (Coord.) (2004) La clausura femenina en España, San Lorenzo del Escorial, Real Centro Universitario Escorial-María Cristina. 
- (Coord.) (2011) La clausura femenina en el Mundo Hispánico: una fidelidad secular, San Lorenzo del Escorial, Real Centro Universitario Escorial-María Cristina.

Canet Aparisi, T. (1990) La Magistratura valenciana (s. XVI-XVII), Valencia, Universitat de València.

Cerdá Ballester, J. (2012) Els cavallers i religiosos de l'orde de Montesa en temps dels Àustria (1592-1700), Tesis Doctoral inédita, Valencia, Universitat de València.

Cortabarria Beitia, A. (1970) «El estudio de las lenguas en la orden dominicana», Estudios filosóficos, 24 , pp. 79-127 y 359-392.

Diago, F. (1599) Historia de la Provincia de Aragón de la orden de Predicadores, desde su origen y principio hasta el año de mil y seyscientos, Barcelona, Sebastián Cormellas.

Egido, T. (2007) «Historiografía del clero regular en la España Moderna», en A. Cortés Peña y M. L. López- Guadalupe Muñoz (Eds.), La Iglesia española en la Edad Moderna. Balance historiográfico y perspectivas, Madrid, Abada Editores.

Esponera Cerdán, A. (1996) «La escuela historiográfica del convento de Predicadores de Valencia en el siglo XVIII», en Qué es la Historia de la Iglesia, Pamplona, Eunsa, pp. 397-420.

- (2003) «Aproximación a la historiografía dominicana ibérica desde el Renacimiento hasta la Ilustración (siglos XVI-XVIII)», Archivo Dominicano, XXIV, pp. 107-148.

Felipo Orts, A. (1991), La Universidad de Valencia durante el siglo XVII (1611-1707), Valencia, Universitat de València.

- (2002) «La ascensión social de los Cervelló: de barones de Oropesa a condese de Cervelló y Grandes de España». Estudis, 28, pp. 241-262

- (2007a) «El testament del marqués de Villatorcas i la disputa del comte de Cervelló per l'herència paterna. Una altra conseqüència de l'exili austriacista». Aguaits, 24-25, pp. 97-121.

—. (2007b) El conde de Cervelló y el Consejo de Italia, Valencia, Alfons el Magnànim.

Fogués Juan, F. (1934) Historia de Carcagente: compendio geográfico-bistórico de esta ciudad. Carcaixent, s.e.

Fuentes, C. (1930) Escritores dominicos del reino de Valencia, Valencia, Ángeles Pitarch.

Garganta, J. Ma . (1957) «Los dominicos de la Provincia de Aragón en la historia de la espiritualidad (siglos XIV-XVII)», Teología espiritual, 1, pp. 98-121.

. (1965) «Apuntes sobre el momento tridentino de la Provincia de Aragón», en Atti del Il Concilio di Trento e la reforma tridentina, Roma, s.e., : II, pp. 643-646.

Gómez Orts, L. (2011) «Aproximación socio-biográfica a una familia de juristas valencianos: los Sisternes «, Estudis. Revista de Historia Moderna, 37, pp. 511-527.

- (2012) «Administrar y juzgar desde la Cancillería de un reino. La gestión del regente valenciano Melchor Sisternes de Oblites (1629 - 1632)», en M. J. Pérez Álvarez y A. Martín García (Eds.). Culturas políticas en el Mundo Hispánico, León, Universidad de León, pp. 1567-1579.

Martínez Ruiz, E. (Dir) (2004) El peso de la Iglesia. Cuatro siglos de órdenes religiosas en España, Madrid, Actas.

SCRIPTA, Revista internacional de literatura i cultura medieval i moderna, núm. 8 / desembre 2016 / pp. 224-240 
Moreno Burriel, E. (1990), «Patrimonio Artístico. Los Retablos de Carcaixent», en Carcaixent. Festes Patronals, Carcaixent, s.e.

Orellana, M. A. de (1930) Biografía pictórica valentina o Vida de los pintores, arquitectos, escultores y grabadores valencianos, Madrid, Gráficas Marinas.

Poutrin, I. (1995) Le voile et la plume. Autobiographie et saintité féminine dans l'Espagne Moderne, Madrid, Biblioteca Casa Velázquez.

Ramis Barceló, R. \& Cassanyes Roig, A. (2014) «Los graduados en Artes y Filosofía en la Universidad Luliana y Literaria de Mallorca I: (1692 - 1750)». Tiempos Modernos, 28, pp. 12 -48.

Reder Gadow, M. (2000) «Las voces silenciosas de los claustros de clausura». Cuadernos de Historia Moderna, 25, pp. $279-338$.

Robles Sierra, A. (1983) «La reforma entre los dominicos de Valencia en el siglo XVI», en Corrientes espirituales en la Valencia del siglo XVI (1550 - 1600), Valencia, Facultad de Teología «San Vicente Ferren», pp. 183-210.

_. (1992) Real monasterio de Santa Catalina de Siena. Proyección y fidelidad. Valencia, Dominicos Provincia de Aragón.

Sanchis Sivera, J. (1922) Nomenclátor geográfico-eclesiástico de los pueblos de la diócesis de Valencia, Valencia, M. Gimeno.

Sempere, L. G. (1903) Vida de la venerable madre sor Inés de Sisternes, dominica, Almería, Non plus ultra.

Teixidor, J. (1895) Antigüedades de Valencia, Valencia, Francisco Vives Mora. 2 vols.

Tormo, E. (1923) Guía de Levante, Valencia, s. e.

Viforcos Marinas, Ma . I. (Coord.) (2000) Historias compartidas. Religiosidady reclusión femenina en España, Portugal y América, siglos XV - XIX, León, Universidad de León

Viforcos Marinas, Mª I. \& Campos Sánchez-Bordona, Ma . D. (Coords.) (2005) Fundadores, fundaciones y espacios de vida conventual: nuevas aportaciones al monacato femenino, León, Universidad de León.

Vitse, M. (Coord.) (2005) La hagiografía entre historia y literatura en la España de la Edad Media y del Siglo de Oro: homenaje a Henri Guerreiro, Pamplona, Iberoamericana. 